\title{
EUS-guided choledochoduodenostomy for biliary drainage using tapered-tip plastic stent with multiple fangs
}

A 52-year-old man presented with abdominal pain and jaundice for 2 months. Computed tomography (CT) revealed a huge mass at the pancreatic head causing distal common bile duct (CBD) obstruction with superior mesenteric vein and superior mesenteric artery encasement (๑ Fig. 1).

The man underwent endoscopic retrograde cholangiopancreatography (ERCP), but we could not pass the duodenoscope through the duodenum because of tumor invasion. Therefore, a self-expandable metallic stent (SEMS) (Wallstent TM; Boston Scientific, Maryland, USA) was inserted. He underwent ERCP 2 weeks later but the ampulla was obscured. Therefore, endoscopic ultrasound (EUS) was considered for internal biliary drainage. The EUS showed a complex mass, $5.2 \times 3.3 \mathrm{~cm}$, at the pancreatic head, and the $\mathrm{CBD}$ was $2.05 \mathrm{~cm}$ ( Fig. 2).

After EUS-guided cholangiography, tailormade Teflon dilators - 7 and 8.5 Fr - were used for dilation over the wire ( $\bullet$ Figs. 3 and 4).

Then an $8.5 \mathrm{Fr} \times 6.5 \mathrm{~cm}$ tailormade tapered-tip plastic stent, with multiple fangs but without a side hole, was inserted, and gave satisfactory drainage ( $\bullet$ Figs. 5 and $6)$.

The patient was discharged without any complications. He was scheduled for SEMS insertion 4 months later.

In advanced pancreatic cancer, such as this case, percutaneous transhepatic biliary drainage (PTBD) and surgical drainage are the alternative options. PTBD is reported to have a higher complication rate of $10 \%-30 \%$, while surgery is associated with a $2 \%-5 \%$ mortality and $17 \%-37 \%$ morbidity [1]. Even though EUS-guided biliary drainage was reported to be the safe and feasible procedure [2,3], it is not widely used because it requires more-advanced endoscopic skills. Possible complications of the EUS-guided biliary drainage, for example bile leakage and pneumoperitoneum, have also been reported. We minimized the leakage in this case by using a dilator instead of a needle knife or balloon dilation. We made the plastic stent ourselves instead of using a commercial one to make stent insertion easi-

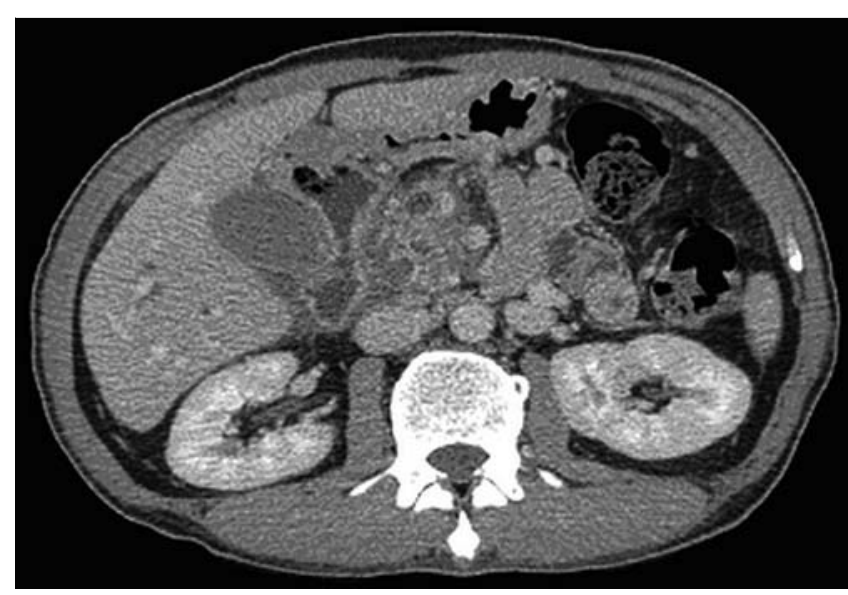

Fig. 1 Computed tomography (CT) scan showing pancreatic mass at head and common bile duct, and pancreatic duct dilatation.

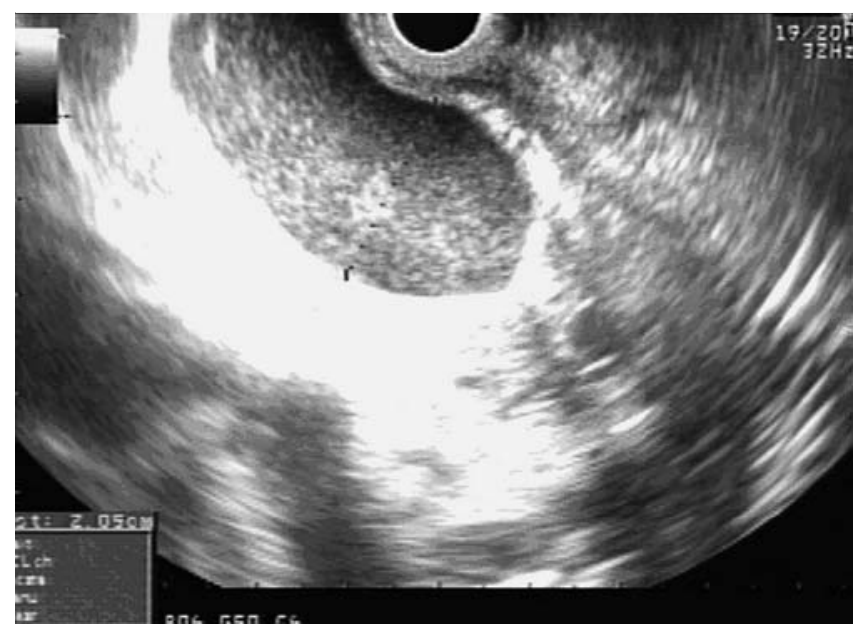

Fig. 2 Endoscopic ultrasound showed the common bile duct, $2.05 \mathrm{~cm}$.

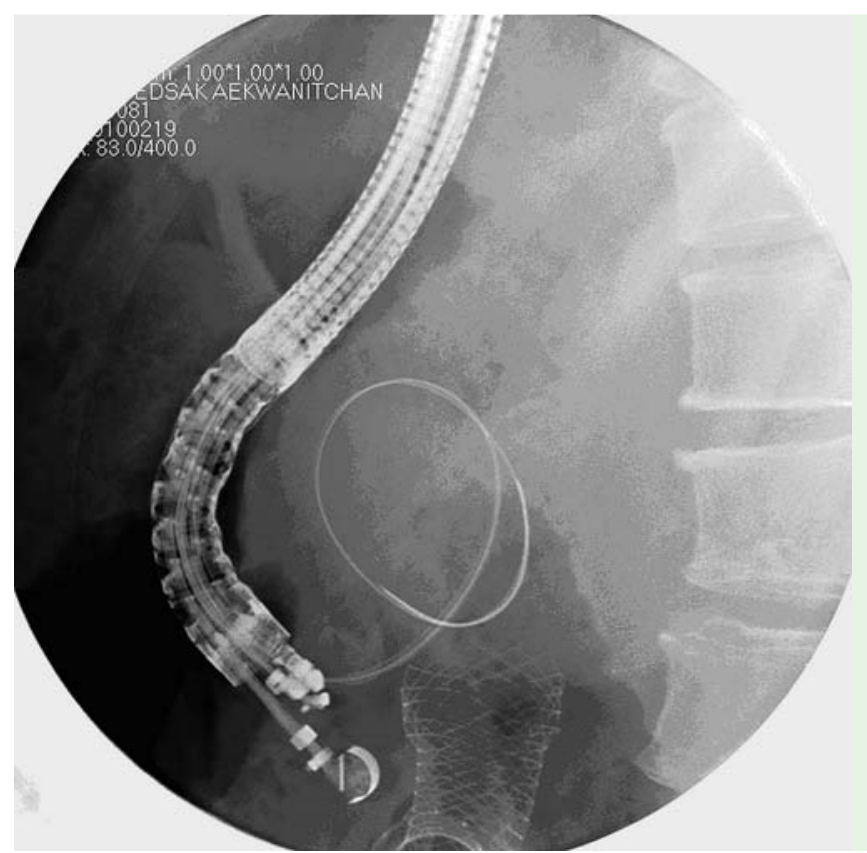

Fig. 3 Dilatation of the common bile duct. 

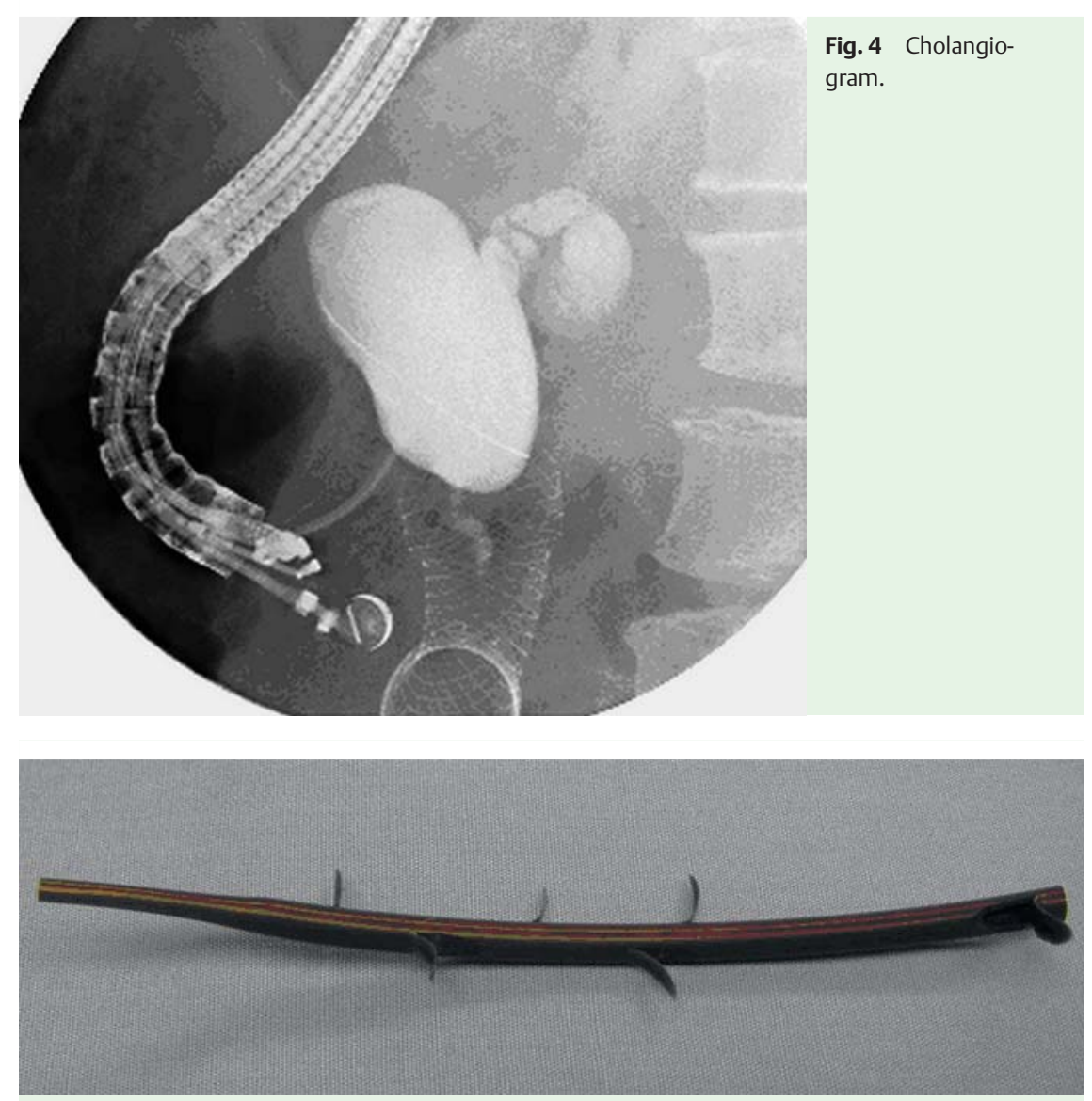

Fig. 5 Our tailormade tapered-tip plastic stent with multiple fangs and no side hole.

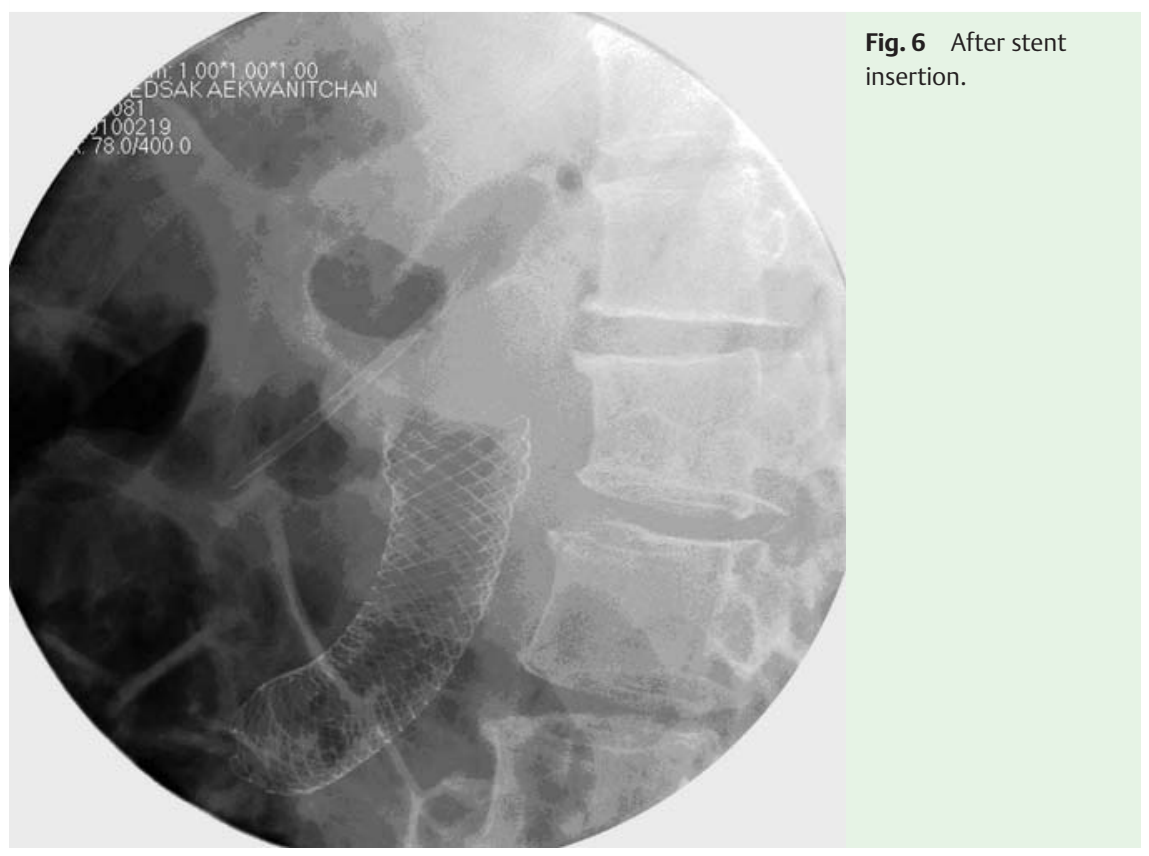

er, prevent bile leakage, and prevent CBD injury during stent insertion. Our idea of multiple fangs without a side-hole was to prevent stent migration and early clogging.

\section{Endoscopy_UCTN_Code_TTT_1AS_2AD}

\section{Competing interests: None}

\section{Prachayakul ${ }^{1,2}$, P. Aswakul ${ }^{2}$, U. Kachintorn ${ }^{1,2}$}

1 Division of Gastroenterology, Department of Internal Medicine, Siriraj Hospital, Mahidol University, Bangkok, Thailand

2 Vikit Viranuwatti Endoscopy Center, Siriraj Hospital, Mahidol University, Bangkok, Thailand

\section{References}

1 van Delden OM, Lameris JS. Percutaneous drainage and stenting for palliation of malignant bile duct obstruction. Eur Radiol 2008; 18: $448-456$

2 Savides TJ, Varadarajulu S, Palazzo L. EUS 2008 Working Group document: evaluation of EUS-guided hepaticogastrostomy. Gastrointest Endosc 2009; 69: S3 -S6

3 Itoi T, Sofuni A, Itokawa $F$ et al. Endoscopic ultrasonography-guided biliary drainage. J Hepatobiliary Pancreat Surg 2010; 17: 611-616

\section{Bibliography}

DOI $10.1055 / \mathrm{s}-0030-1256140$

Endoscopy 2011; 43: E109-E110

(c) Georg Thieme Verlag KG Stuttgart · New York . ISSN 0013-726X

\section{Corresponding author \\ P. Aswakul}

Department of Internal Medicine

Siriraj Hospital

BangkokNoi

Bangkok 10711

Thailand

Fax: +66-2-4299672

asawakul@gmail.com 